\title{
Ideology in Translation: Theories and Reflections
}

\author{
Lei Dai \\ Department of Translation and Interpretation \\ School of Foreign Languages \\ Wuhan University of Technology \\ Wuhan, China
}

\begin{abstract}
This study aims at examining a burgeoning approach in Translation Studies: ideology. By comparing the conventionally linguistic approach with the ideological approach and by reviewing some of the seminal theories from the ideological perspective, the paper critically reflects on the advantages and disadvantages of ideology in translation, principally finding that the ideological approach while emphasizing contextualization of translation activities, tends to neglect text itself and the assumption of using translation strategies to manipulate language influence also lacks sufficient grounds. The paper is thus original by proposing that it is the economic status that determines the survival and development of a minority language and by calling for attention to the importance of integrating text and context when researching translation.
\end{abstract}

Keywords_ideology; translation; foreignizing; domesticating; minority languages

\section{INTRODUCTION}

With the development of the cultural turn in Translation Studies, scholars from the ideological viewpoint and based on the analysis of communication between major cultures and minority cultures, argue that since its inception, translation as an intercultural human communication, has been subjected to such factors as power, institution, history, ideology and, that the selection of translation strategies exerts a dramatic impact on cross-cultural communication. Thus research on translation strategies has expanded from the linguistic perspective to the ideological perspectives (cf. Bassnett and Trivedi, 1999; Venuti, 1995, 1998; Kwiecinski, 1998; Cronin, 2003) [1] [11] [12] [7] [2]. This paper will introduce and reflect on representative ideological theories.

\section{REPRESENTATIVE THEORIES}

\section{A. Jacquemond's opposition to hegemony in translation}

Jacquemond (1992: 139-158) [4] vehemently criticized cultural hegemonists' distortion and vilification of minority cultures through translation. It should be noted that here minority cultures are in comparative terms with hegemony or dominant cultures between specific cases. For example, "In Egypt, during the French occupation (1798-1801), translation into Arabic had been a major tool in the hands of the occupying forces in order to assert their grip on the country" (Jacquemond, 2009: 2) [5]. So at that specific time, French compared with Arabic is a hegemonic culture. After analyzing a great number of the French versions of the Arabic source texts, he found that those French scholars calling themselves as Orientialists, in the cloak of the "exact science" (Jacquemond, 1992: 149) [4], intentionally amplified the cultural and linguistic differences when translating Arabic texts into French. Paradoxically, the French versions look exactly "scientific" as they were all translated through literally and most simple source expressions were modified and supplemented with sheets of notes, comments and glossaries.

It is argued that translation is comprehensive (including contexts and texts), open (including subjective and objective uncertainties), dynamic (changing with varied contexts and the target receptors' purposes) and human-brain-involved (including the minds of the translator and the interlocutors). So it gains nowhere (cf. Nida, 1964: 156; Koller, 1995: 200; Toury, 1995: 61) [8] [6] [10] to quantify Translation Studies by transferring into it the precision of $1+1=2$ pursued by natural scientists. Orientalists knew this, but they still maliciously slandered minority cultures and asserted cultural hegemony under the pretext of pursuing the exactness of natural sciences. Therefore, literal translation, similar as the foreignizing translation strategy summarized by this research, in Jacquemond's opinion, was employed as a weapon by powerful major cultures against minority cultures. In contrast, Venuti (1995; 1998) [11] [12] insisted on using foreignizing when minority literary texts are translated into dominant cultures. Next, the researcher will review Venuti's major arguments before elucidating the reasons for the polarized opinions held by Jacquemond and Venuti for the foreignizing strategy.

\section{B. Jacquemond vs. Venuti}

Venuti aggressively advocated studying the selection of translation strategies from the ideological perspective. Venuti (1995) [11] categorized translation strategies as "foreignizing" and "domesticating". "Domestication is often used to refer to the adaptation of the cultural context or culture-specific terms, and foreignization to the preserving of the original cultural context, in terms of settings, names and so forth".

He steadfast opposed domesticating minority literary works to English cultures, condemning it as "a strategic cultural intervention" to international relations as well as an "ethnocentric violence" (1995: 20) [11] of the English culture to foreign texts. It is thus evident that standing on the side of minority cultures, he was to deconstruct the English culture which holds sway over other cultures. Venuti reiterated in translation, the linguistic and cultural features of minority works should be highlighted while the "transparent and fluent 
English discourse" (1995: 21) [11] should be opposed. With regard to their disparate attitudes (Venuti "for" and Jacquemond "against") towards the same strategy (foreignizing) for the same translation direction (minority to dominant cultures), reflections are made as follows.

To begin with, it is essential that the translator should select and use strategies properly because superiority does not apply to translation strategies per se. As a practical strategy, if used flexibly, foreignizing can introduce to the target text fresh source cultural elements, but if used mechanically to the extreme of word-for-word translation, the same strategy may make the version obscure and tongue-twisting, which will lose favour from readers. Venuti confessed that his own translated works were rejected by many literary magazine presses due to his adherence to foreignizing. Likewise, the French versions mentioned by Jacquemond were unreadable because of excessive foreignizing.

Secondly, the translator's subjectivity plays an indispensable role in the selection of translation strategies with its display contextualized. The Manipulation School in the area of literary translation argued every translation will to a certain extent manipulates and rewrites the source text for a purpose (Hermans, 1995: 217) [3]. The translators in his view were French Orientalists whose translation purpose was to deliberately defame Oriental works with exaggerated foreignizing and biased notes in the cloak of exact science. On the contrary, the translators inspired by Venuti to adopt foreignizing mostly represent minority cultures, for the aim of "restraining the ethnocentric violence of the English cultures" (Venuti, 1995: 21) [11]. Obviously, standing on polarized cultural and ideological grounds, the translator will invariably manipulate or rewrite the source text in order to hype her represented culture, be it dominant or minor.

The paper argues despite the influence of subjectivity on translation strategic selection, the translation position, purpose and linguistic choices of any sensible, ethical, qualified translator will to a large extent be determined by the source text and the greater contexts because the translator's subjectivity invariably reflects and conforms to the objective needs and settings. As Robinson puts (2001: 87) [9], "translators are not autonomous individuals producing translations like omnipresent gods out of fullness of their world mastery...rather; they are parts of a larger number of translatorial agencies". This being said, the paper argues that on one hand subjectivity of the translator cannot be totally neglected; its existence is natural. On the other hand, any selection of translation strategies are constrained and influenced by the ad-hoc contexts. So there are some scholars arguing study translation given its direction.

\section{Kwiecinski and Cronin's emphasis on translation direction}

The Polish scholar Kwiecinski (1998: 188) [7] argued that to judge if the foreignizing strategy is to resist or promote cultural imbalances and hegemony, the key is the direction of translation. He found out $69 \%$ of the English and American culture-specific terms were foreignized with over $30 \%$ borrowed intact from the source language, based on a decadal corpus analysis of Polish translated versions since the Soviet collapse in 1991. The assimilating impact of English on Polish was even more tremendous than those European languages that had been long influenced by English, with English words, grammar and other linguistic usages invading into Polish despite only a decade since Poland was opened to West.

Kwiecinski pointed out Polish culture and language are so vulnerable in their communication with English and American cultures which dominate Western cultures while the Polish national norms, beliefs and ways of behaviour that used to hold sway in the nation succumbed to the hegemonic cultures and are gradually marginalized. Evidently, foreignizing in Poland has been playing a role of absorbing floods of British and American ways of living and thinking which gradually displace the aboriginal culture and language. So, only by adopting domesticating can cultural hegemony be "strategically intervened" (Kwiecinski, 1998: 203) [7].

The Irish translation theorist Cronin also emphasized that when translating minority works to dominant cultures, the source cultural and linguistic features be retained, so much so that the translation reads like "a reflexion rather than a reflection" (Cronin, 2003: 141) [2] of the source text. This means that the translator needs to take the initiative to take the translation process seriously so that the translation sounds with its own life and features. Otherwise, if the translation is a mere reflection of the ST, ie. mirroring the ST, it is not considered by Cronin as a positive translation.

Conversely, when translating dominant cultural works into minority cultures, the "naturalizing strategy" (Cronin, 2003; namely the domesticating strategy) [2] serves as the key to the survival of minority cultures. Cronin based his opinions on the parlous state of many minority languages in the modern world. As for the Irish language, by the end of the 16th century, $90 \%$ of the Irish population were Irish-speaking, now less than $10 \%$ are fluent in the language and "there are virtually no Irishspeaking monoliths left" (Cronin, 2003: 142) [2]! Therefore, Cronin, in the shoes of minority languages endangered, insisted on considering translation as diversification instead of assimilation.

\section{CRITICISMS AND REFLECTIONS}

This paper argues that it conforms to the reality of translation by studying translation strategies from such macro perspectives as politics, culture, society, history, and ideology, rather than from the micro perspective of linguistic features of the text alone, because studies in this area cannot overlook the specific contexts where translation, "a real-time, intercultural and social communicative act" (Williams, 2013) [13], is engaged. Yet two doubts are cast upon the above studies.

Firstly, has it gone too far to study translation strategies from the greater context perspective, so much so that, the source text is almost ignored? This study maintains that when studying translation strategies, it is reasonable to analyze the source text and the translation in the specific source and target contexts, regardless of interpreting or translating, literary or practical translation. We will run to either extreme if one (the text) is overemphasized while the other (the context) is trifled with. This paper supports studying translation strategies from a 
higher altitude above the source text, but not totally detached from it. Otherwise, such general and abstract ideas as institution, ideology and power may not guide specific translation practices effectively. In a word, this study believes that the studies on translation strategies as well as the translation process be conducted simultaneously by integrating the source text with dynamic contexts, languages with cultures, and macro perspective with micro perspective.

Secondly, what is the point of emphasizing the protection of weak minority cultures and languages through the selection of translation strategies? This paper posits that the survival and development of the cultures and languages of certain ethnicities comply with the survival of the fittest evolutionary principle. The reasons for the extinction of a specific language and culture can be manifold. Today, with the ever-growing economic, cultural and technological globalization, for faster development, it is mandatory for minority ethnicities to get on track with the rest of the world and modify and sacrifice part of their own languages and cultures through intercultural communication.

In terms of the purity of language and culture, we might echo Kwiecinski that the Polish language and culture is almost westernized and finished. Rather, we might also argue that since its door thrown open to the West, in particular after its entry into the EU in 2004, its economy has been developing at full swing with the livelihood of its citizens enhanced with each passing day. From the perspective of Marxist political economics, the economic base determines the political and cultural superstructures. Only with a developed or fastdeveloping economy can a nation enjoy stable political/social situation and further boost its causes of language and culture.

\section{CONCLUSION}

Therefore, this paper argues that it is a parochial and impractical attempt to defend and hype one's national culture by exaggerating the translator's discretion or certain translation strategies. Reading barriers may occur if minority literary works are excessively foreignized, which may incur the target readers' doubts and grudges. Conversely, blind domestication of British and American cultures to minority cultures may disappoint the target readers who are willing to learn more about the source culture.

\section{REFERENCES}

[1] S. Bassnett and H. Trivedi, Postcolonial Tradition: Theory and Practice. London and New York: Pinter, 1999.

[2] M. Cronin, Translation and Globalization. London and New York: Routledge, 2003.

[3] T. Hermans, Revisiting the Classics: Toury's Empiricism Version One. The Translator, vol. 2, pp.215-223, 1995.

[4] R. Jacquermond, Translation and Cultural Hegemony: The Case of French-Arabic Translation. In L. Venuti (ed.). Rethinking Translation: Discourse, Subjectivity, Ideology. pp.139-159. London and New York: Routledge.

[5] R. Jacquermond, Translation Policies in the Arab World. The Translator, vol.1, p1-21, 2009.

[6] W. Koller, The Concept of Equivalence and the Object of Translation Studies. Target, vol.2, p191-222, 1995.

[7] P. Kwiecinski, Translation Strategies in a Rapidly Transforming Culture: A Central European Perspective. The Translator, vol.2, p183-206, 1998.

[8] E. A. Nida, Toward a Science of Translating, Leiden: E. J. Brill, 1964.

[9] D. Robinson, Who Translates: Translator Subjectivities beyond Reason. New York: State University of New York Press, 2001.

[10] G. Toury, Descriptive Translation Studies - And Beyond. Amsterdam and Philadelphia, PA: John Benjamins, 1995.

[11] L. Venuti, The Translator's Invisibility: A History of Translation. London and New York: Routledge, 1995.

[12] L. Venuti, The Scandals of Translation: Towards an Ethics of Difference. London and New York: Routledge, 1998.

[13] J. Williams, Theories of Translation. New York: Palgrave Macmillan, 2013. 